\title{
Visual Recognition of Child Body Mass Index by Medical Students, Resident Physicians, and Community Physicians Carolyn R. Ahlers-Schmidt, Ph.D. ${ }^{1}$, Deborah Kroeker, M.D. ${ }^{1}$, Amy Chesser, Ph.D. ${ }^{2}$, Traci Hart, Ph.D. ${ }^{2}$, Jennifer Brannon, M.D. ${ }^{1}$ University of Kansas School of Medicine-Wichita \\ ${ }^{1}$ Department of Pediatrics \\ ${ }^{2}$ Department of Preventive Medicine and Public Health
}

\begin{abstract}
Background: Many studies have assessed the ability of mothers to identify their child's Body Mass Index (BMI) category and the vast majority of mothers are unable to do so accurately. This suggested a need for physicians to inform parents about their child's weight status. However, many physicians do not chart BMI-for-age, even though it is recommended. Instead they rely on their visual perception of the patient's weight status. This study determined the number of medical students, resident physicians, and community physicians who correctly categorize preschool children into their appropriate weight class by visual cues alone.

Methods: Fourth-year medical students, family medicine and pediatric resident physicians, and family medicine and pediatric community physicians completed a brief on-line survey. Pictures of three preschool children were shown and respondents described each child's BMI-for-age category.

Results: A 43\% (134/312) response rate was achieved. Only $15 \%$ of respondents correctly identified a 3-year-old boy, whose BMI was $>95^{\text {th }}$ percentile for his age, as obese. Nearly $86 \%$ correctly identified a 4 -year-old girl with normal BMI-for-age, but only $21 \%$ correctly identified another girl who was overweight at the $90-95^{\text {th }}$ percentile BMI-for-age. No significant difference was found in total accuracy between medical students, resident physicians, or community physicians $(\mathrm{F}(2,123)=0.743, \mathrm{p}=0.478)$ or between family medicine physicians and pediatricians $(\mathrm{F}(1,107)=2.269, \mathrm{p}=0.135)$ when predicting the BMI-for-age categories.

Conclusions: Medical professionals and trainees have difficulty visually assessing a child's BMI-for-age weight status. This underscores the importance of calculating and plotting BMI at healthy check-ups.
\end{abstract}

KJM 2010; 3(5):7-14.

\section{Introduction}

The importance of early identification of weight problems is clear based on the 2003 American Academy of Pediatrics (AAP) Policy Statement on the Prevention of Pediatric Overweight and Obesity, which was also reaffirmed in 2007. ${ }^{1}$ The report stated Body Mass Index (BMI) should be calculated and plotted, and urged pediatricians to educate and empower families to raise healthy children. However, studies have shown that physicians do not regularly assess $\mathrm{BMI}^{2-5}$, especially in young children. ${ }^{5}$ This is disturbing as physicians tend to underestimate children's weight categories when using only visual cues. ${ }^{2,6}$

Early identification and treatment are keys to improving health and decreasing risk of long-term health issues. Many providers are more likely to identify obesity in older children (with higher BMI percentiles), therefore missing opportunities for early interventions. ${ }^{7}$ In a study of pediatric subspecialists, children less than five years of age were less likely to receive a diagnosis 
of overweight. ${ }^{8} \quad$ Yet, obesity interventions with children aged 3 to 5 years were more likely to be successful. ${ }^{9}$ Therefore, it can be concluded that to treat this medical condition, it is necessary to recognize and identify the problem early.

Parents who were aware that their child's weight was a health problem were more likely to make positive changes than those who did not recognize the problem. ${ }^{10}$ Also, parents were more likely to identify weight issues in their child if their doctor had addressed the child's weight. ${ }^{11}$ In addition, physician identification of obesity correlated with increased time spent counseling patients. $^{2}$ These findings suggested physicians and healthcare workers may have an "ethical obligation" to identifying children who are overweight and sensitively educate parents when treating their overweight child. ${ }^{10}$

Correctly identifying and approaching obesity early allows children to be medically managed better. Children clearly identified as overweight in their medical records were more likely to have had laboratory testing than overweight children not identified. ${ }^{7}$ In addition, children identified as overweight were more likely to have appropriate medical evaluations for comorbid conditions associated with obesity and earlier interventions for those conditions. ${ }^{7,8}$

Because parents have difficulty accurately categorizing children's weight status ${ }^{6,12}$, it is imperative that physicians can identify obese children to counsel parents regarding their child's condition. ${ }^{10}$ The problem of pediatric obesity may be common, but it should not be considered "normal".

Physicians should maintain a healthy mental image of appropriate weight and generally be able to identify overweight or obese children by visual cues. This may be especially challenging for resident physicians and medical students, as they represent a group of people who have grown up surrounded by increasing rates of overweight and obesity, therefore, may be desensitized. One study concluded that "children and adolescents who live in environments in which people they see on a daily basis, such as parents and schoolmates, are overweight/obese may develop inaccurate perceptions of what constitutes appropriate weight status". 13

A review of the literature identified no studies that assessed the ability of students or resident physicians to identify weight status accurately. Therefore, this study aimed to evaluate whether community physicians, resident physicians, and medical students are able to categorize preschool children correctly into their appropriate weight class by visual cues alone, and whether there appears to be a difference in accuracy based on training level.

\section{Methods}

All fourth-year medical students, family medicine and pediatric resident physicians, and family medicine and pediatric physicians in Sedgwick County, Kansas (a single geographic area), were included in the survey. Institutional Review Board approval was obtained from both the university and hospital.

SurveyMonkey $y_{\odot}$ was used to send an electronic survey to each potential respondent. A reminder e-mail with the link was sent every two weeks to nonrespondents, with a maximum of two reminders after the initial e-mail. Consent was implied by the respondent's willingness to answer the survey.

The survey began by inquiring about the respondent's confidence in his/her ability to identify a child's BMI-for-age-category accurately and beliefs regarding the importance of BMI-for-age status on children's health. The survey proceeded to ask the respondent to rate their perception of 
the following groups of people on their level of accuracy for visually assessing a child's BMI-for-age: parents, family medicine physicians, pediatricians, nurses, and elementary teachers. Respondents then were asked if they thought different races/ ethnicities perceive children's weights differently, and if so, which race is the least accurate in describing a child's weight.

Pictures of three preschool children were shown. The pictures were the same as ones used in the US Center for Disease Control and Prevention internet-based training on using the BMI-for-Age Growth Charts. ${ }^{14}$ The respondent was asked to describe each child's BMI-for-age category using only visual cues (see Figure 1). The weight category choices were underweight $\left(<5^{\text {th }}\right.$ percentile), normal weight $\left(5^{\text {th }}\right.$ to $<85^{\text {th }}$ percentile), overweight $\left(85^{\text {th }}\right.$ to $<95^{\text {th }}$ percentile), and obese ( $\geq 95^{\text {th }}$ percentile). The survey concluded by obtaining basic demographic information on the respondents, including age, sex, race, medical training and specialty (or intended specialty if the respondent was a medical student.)

Data analysis was completed using the Statistical Package for the Social Sciences (SPSS) version 15.0. Frequencies were computed for categorical data while means and standard deviations were computed for continuous data. Because age was not normally distributed, the median also was reported. For additional analysis, ANOVA was computed to assess total accuracy (sum of correct responses) by level of profession (student, resident physician, or physician) and chi square was used to compare accuracy regarding individual pictures with respondent's gender and confidence level. Due to the low number of respondents for the two extreme categories, the respondents who felt "very confident" were collapsed into "confident" and those who were "somewhat confident" were collapsed into "not confident" for the chi-square analyses to allow Fisher's Exact corrections.

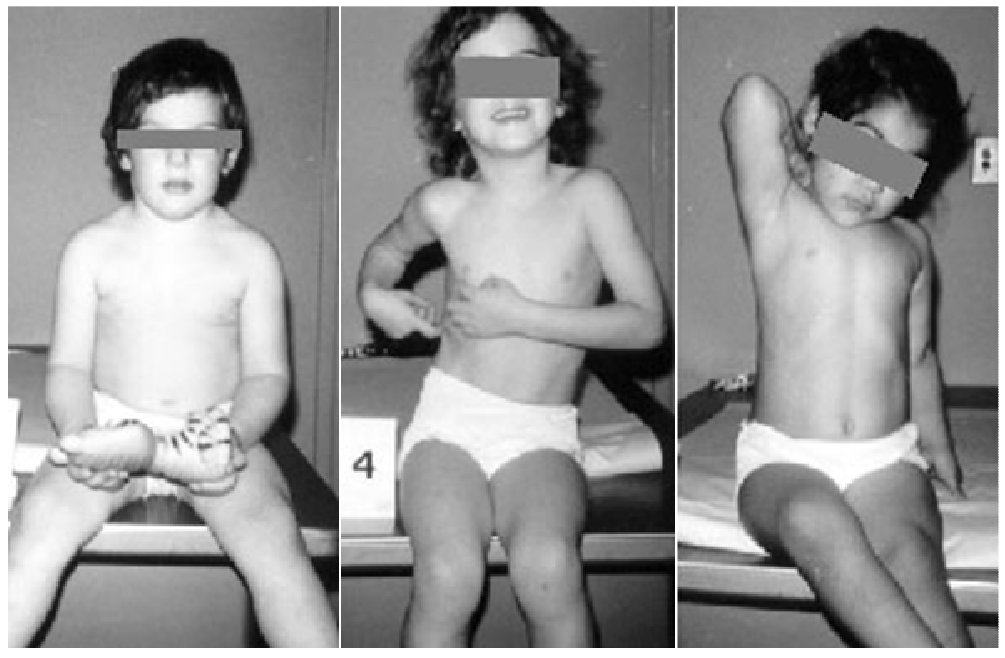

Figure 1. Body mass index Growth Grid Training Module pictures from left to right: an obese male child, a normal-weight female child, and an overweight female child. (Pictures used with permission from the UC Berkeley Longitudinal Study, 1973) ${ }^{14}$ 


\section{Results}

Of the 312 surveys, 134 were completed, resulting in a response rate of $42.9 \%$ (see Table 1). Over $81 \% \quad(109 / 134)$ of respondents indicated they were not confident in their abilities to predict a BMIfor-age category for a child by visual cues accurately, while the remaining $19 \%$ (25/134) were confident. Nearly all (95.5\%; 127/133) respondents indicated that BMIfor-age status is either important or very important for children's overall health.

Over half of the respondents (51.6\%; $67 / 130)$ reported that pediatricians visually were able to assess a child's BMI-for-age status accurately, while about one-third of

respondents $(36.1 \%$; 47/130) indicated that family medicine physicians were able to do so (see Figure 2). Respondents were varied on their confidence in a nurse's ability to assess a child's BMI-for-age status accurately, while they were even less confident in elementary school teachers' abilities. Only 3\% (4/134) of respondents reported that parents visually were able to assess their child's weight accurately. Further, 97\% (130/134) of respondents indicated that different ethnicities perceive children's weight differently, with Hispanics as the least accurate in describing a child's weight, followed by African Americans.

Table 1. Percent (number) of respondent's demographic characteristics and confidence ratings.

\begin{tabular}{|c|c|c|c|c|}
\hline & $\begin{array}{c}\text { Total } \\
(n=134)\end{array}$ & $\begin{array}{c}\text { MS4 } \\
(\mathrm{n}=20)\end{array}$ & $\begin{array}{c}\text { Resident } \\
\text { Physician } \\
(\mathrm{n}=54)\end{array}$ & $\begin{array}{c}\text { Community } \\
\text { Physician } \\
(\mathrm{n}=52)\end{array}$ \\
\hline \multicolumn{5}{|l|}{ Sex } \\
\hline Male & $51.5 \%(69)$ & $25.0 \%(5)$ & $51.9 \%(28)$ & $50.0 \%(26)$ \\
\hline Female & $44.8 \%(60)$ & $75.0 \%(15)$ & $48.1 \%(26)$ & $50.0 \%(26)$ \\
\hline \multicolumn{5}{|l|}{ Race } \\
\hline Caucasian & $88.7 \%(110)$ & $90.0 \%(18)$ & $86.0 \%(43)$ & $90.2 \%(46)$ \\
\hline African American & $2.4 \%(3)$ & $5.0 \%(1)$ & $2.0 \%(1)$ & $2.0 \%(1)$ \\
\hline Hispanic & $4.0 \%(5)$ & $0.0 \%(0)$ & $4.0 \%(2)$ & $5.9 \%(3)$ \\
\hline Asian American & $4.8 \%(6)$ & $5.0 \%(1)$ & $8.0 \%(4)$ & $2.0 \%(1)$ \\
\hline \multicolumn{5}{|l|}{$\begin{array}{l}\text { Specialty/Intended } \\
\text { Specialty }\end{array}$} \\
\hline Family Practice & $53.7 \%(72)$ & $25.0 \%(5)$ & $66.7 \%(36)$ & $59.6 \%(31)$ \\
\hline Pediatrician & $30.6 \%(41)$ & $10.0 \%(2)$ & $33.3 \%(18)$ & $40.4 \%(21)$ \\
\hline Other & $9.7 \%(13)$ & $65.0 \%(13)$ & $0.0 \%(0)$ & $0.0 \%(0)$ \\
\hline \multicolumn{5}{|l|}{$\begin{array}{l}\text { Self-Confidence in } \\
\text { Predicting BMI }\end{array}$} \\
\hline Very Confident & $1.5 \%(2)$ & $0.0 \% \quad(0)$ & $0.0 \% \quad(0)$ & $1.9 \%(1)$ \\
\hline Confident & $17.2 \%(23)$ & $15.0 \%(3)$ & $13.0 \%(7)$ & $23.1 \%(12)$ \\
\hline Somewhat Confident & $71.6 \%(96)$ & $70.0 \%(14)$ & $79.6 \%(43)$ & $65.4 \%(34)$ \\
\hline Not Confident At All & $9.7 \%(13)$ & $15.0 \%(3)$ & $7.4 \% \quad(4)$ & $9.6 \%(5)$ \\
\hline
\end{tabular}




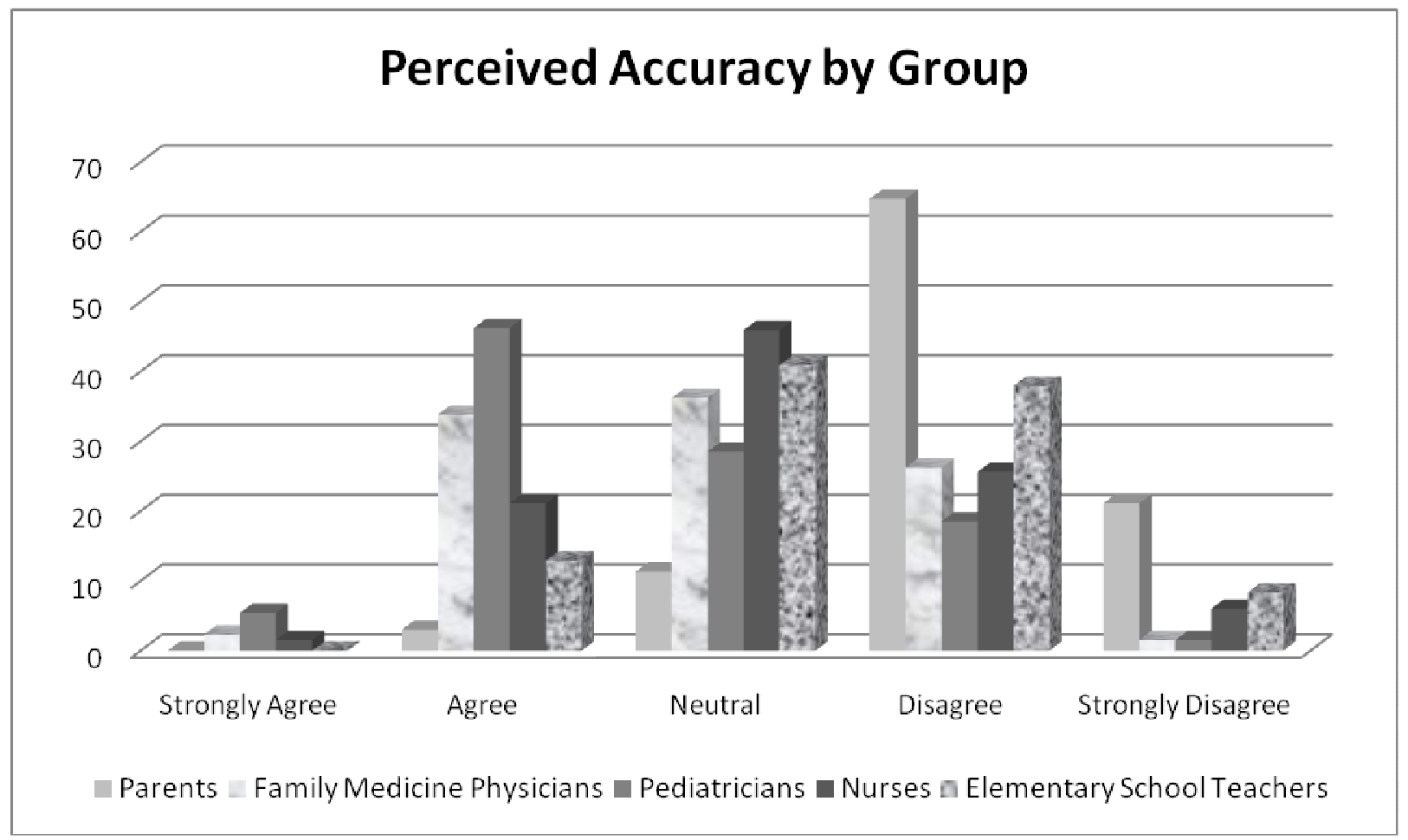

Figure 2. Respondents' beliefs in each group's ability to assess a child's BMI-for-age accurately by visual cues alone (as percents).

Only $14.9 \%$ of respondents (20/134) successfully identified the pictured male, whose BMI is $>95^{\text {th }}$ percentile for his age, as obese (see Table 2). A total of $85.8 \%$ of respondents $(115 / 134)$ placed the pictured normal weight female child in the correct category (normal BMI-for-age at the $10^{\text {th }}$ percentile). For the third pictured child, who is overweight at the $90-95^{\text {th }}$ percentile BMI-for-age, $20.9 \%$ of respondents
(28/134) placed her in the correct BMI-for-age category. "Normal" was the most commonly chosen category for her BMI-for-age.

After separating respondents by training level, the analysis revealed no significant difference in total accuracy between medical students, resident physicians, or community physicians when predicting the BMI-for-age categories $(\mathrm{F}(2,123)=0.743, \mathrm{p}=0.478)$. There

Table 2. Percentages (numbers) of respondents who placed each child into the BMI-for-age categories. Correct responses are shaded.

\begin{tabular}{|l|c|c|c|}
\hline & Obese Male & $\begin{array}{c}\text { Overweight } \\
\text { Female }\end{array}$ & $\begin{array}{c}\text { Normal Weight } \\
\text { Female }\end{array}$ \\
\hline Underweight & $0.0 \%(0)$ & $1.5 \%(2)$ & $11.9 \%(16)$ \\
\hline Normal weight & $23.9 \%(32)$ & $77.6 \%(104)$ & $85.8 \%(115)$ \\
\hline Overweight & $61.2 \%(82)$ & $20.9 \%(28)$ & $1.5 \%(2)$ \\
\hline Obese & $14.9 \%(20)$ & $0.0 \%(0)$ & $0.7 \%(1)$ \\
\hline
\end{tabular}


was no significant difference in total accuracy between family medicine physicians and pediatricians $(\mathrm{F}(1,107)=$ 2.269, $\mathrm{p}=0.135)$; neither was there a significant difference in accuracy for each picture by the respondent's gender $\left(\chi^{2}(1)=0.12, \mathrm{p}=.734 ; \chi^{2}(1)=0.102, \mathrm{p}=.749\right.$; $\chi^{2}(1)=0.716, \quad \mathrm{p}=.397 \quad$ respectively). Additionally, using Fisher's Exact test to compare binary confidence level with accuracy for each picture, results were not significant for the obese male $\left(\chi^{2}(1)=1.99\right.$, $\mathrm{p}=0.210)$ or the normal weight female $\left(\chi^{2}(1)=0.12, p=.508\right)$, however, accuracy in predicting the overweight female's BMI category was affected significantly $\left(\chi^{2}(1)=\right.$ 6.79, $\mathrm{p}=0.013$ ).

\section{Discussion}

This survey found medical professionals and trainees believe BMI-for-age status is important for health. However, our data showed medical professionals and trainees were unable visually to assess a child's BMI-for-age weight status accurately. At best, classification of children by visual assessment can be described as inconsistent. This supported Barlow's 2007 findings ${ }^{3}$ that pediatricians were able to identify only $27 \%$ of children with a BMI between the $85^{\text {th }}$ and 94. $9^{\text {th }}$ percentile. However, the Barlow study also found that $86 \%$ of pediatricians identified children as obese if their BMI was above the $95^{\text {th }}$ percentile for their age, a better rate of recognition than found in our study. An Australian study ${ }^{2}$ found general practitioners correctly categorized children into BMI-for-age classes $72 \%$ of the time, while pediatricians had a $68 \%$ overall correct categorization. Our study contrasted this finding, as there were no statistically significant differences between pediatric and family medicine physicians' abilities to categorize children accurately.

Our results suggested that physicians and trainees recognize the difficulty in assessing BMI category visually, as less than $2 \%$ of respondents felt "very confident" in their ability to assess a child's BMI-forage category just by looking at a child. In addition, over half of respondents felt pediatricians would be accurate and less than $40 \%$ felt family medicine physicians would be accurate. Our study indicated very low confidence in visual assessment by self or other physicians, which is a clear indicator that the AAP's recommendations for charting BMI are not only appropriate, but necessary. Physicians report barriers to charting BMI, such as time and complexity of explaining $\mathrm{BMI}^{5}$, but also endorse innovations, such as color-coded charts, which increase the likelihood of identification and discussion of BMI. ${ }^{4}$ In addition, the use of electronic medical records with automatic BMI computations improved documentation of obesity (BMI $\geq$ 30) by $40 \% .^{15}$

This study had several limitations. The small area (Sedgwick County, KS) of this cross-sectional survey limited the generalizability of the results. Further, physicians are notably poor survey responders $^{16}$ and studies $^{17,18}$ report a dramatic decline in response rates of email surveys. However, email was chosen because it is cost-effective, in both time and monetary savings and results in fewer unanswered items than other modes. ${ }^{19}$ Our response rate was over $40 \%$ after three personalized attempts. According to an article by Schoenman and colleagues ${ }^{20}$, survey results do not differ significantly between $30 \%$ and $60 \%$ response rates, so we closed survey collection two weeks after the third reminder.

Another limitation is the formatting and form of the pictures. The pictures were black-and-white and respondents may have chosen differently had the pictures been in color. All of the pictures were of nonHispanic white children, which also could 
affect perception. Additionally, it is difficult to assess a patient's weight from a photograph, and the children were sitting down which further complicated the assessment. If the children were patients in their own clinics, subjects may have categorized them differently. However, these pictures were used by the US Centers for Disease Control and Prevention for their BMI training and have been used in

\section{References}

${ }^{1}$ Krebs NF, Jacobson MS, American Academy of Pediatrics Committee on Nutrition. Prevention of pediatric overweight and obesity. Pediatrics 2003; 112:424-430.

${ }^{2}$ Spurrier NJ, Magarey A, Wong C. Recognition and management of childhood overweight and obesity by clinicians. J Paediatr Child Health 2006; 42:411-418.

${ }^{3}$ Barlow SE, Bobra SR, Elliott MB, Brownson RC, Haire-Joshu D. Recognition of childhood overweight during health supervision visits: Does BMI help pediatricians? Obesity (Silver Spring) 2007; 15:225-232.

${ }^{4}$ Gilbert MJ, Fleming MF. Use of enhanced body mass index charts during the pediatric health supervision visit increases physician recognition of overweight patients. Clin Pediatr 2007; 46:689-697.

${ }^{5}$ Woolford SJ, Clark SJ, Strecher VJ, Gebremariam A, Davis MM. Physicians' perspectives on increasing the use of BMI charts for young children. Clin Pediatr 2008; 47:573-577.

${ }^{6}$ Chaimovitz R, Issenman $\mathrm{R}$, Moffat $\mathrm{T}$, Persad R. Body perception: Do parents, their children, and their children's physicians perceive body image differently? J Pediatr Gastroenterol Nutr 2008; 47:76-80. previously published studies. ${ }^{21}$ Further, the physician confidence question was asked before the photos were viewed and responses indicated a dearth of conviction that they would be able to identify any child by sight alone successfully. Finally, the respondents were not asked whether they previously had viewed the pictures on the survey.

7 Dilley KJ, Martin LA, Sullivan C, Seshadri R, Binns HJ, Pediatric Practice Research Group. Identification of overweight status is associated with higher rates of screening for comorbidities of overweight in pediatric primary care practice. Pediatrics 2007; 119:e148-e155.

8 Riley MR, Bass NM, Rosenthal P, Merriman RB. Underdiagnosis of pediatric obesity and underscreening for fatty liver disease and metabolic syndrome by pediatricians and pediatric subspecialists. J Pediatr 2005; 147:839-842.

9 O'Brien SH, Holubkov R, Reis EC. Identification, evaluation, and management of obesity in an academic primary care center. Pediatrics 2004; 114:e154e159.

${ }^{10}$ Parry LL, Netuveli G, Parry J, Saxena S. A systematic review of parental perception of overweight status in children. J Ambul Care Manage 2008; 31:253-268.

${ }^{11}$ Rhee KE, De Lago CW, Arscott-Mills T, Mehta SD, Davis RK. Factors associated with parental readiness to make changes for overweight children. Pediatrics 2005; 116:e94-e101.

${ }^{12}$ Baughcum AE, Chamberlin LA, Deeks CM, Powers SW, Whitaker RC. Maternal perceptions of overweight preschool children. Pediatrics 2000; 106:1380-1386.

${ }^{13}$ Maximova K, McGrath JJ, Barnett T, O'Loughlin J, Paradis G, Lambert M. Do 
you see what I see? Weight status misperception and exposure to obesity among children and adolescents. Int $\mathbf{J}$ Obes (Lond) 2008; 32:1008-1015.

${ }^{14}$ US Centers for Disease Control and Prevention. Using the BMI-for-Age Growth Charts. Accessed at: http://www. cdc.gov/nccdphp/dnpa/growthcharts/traini ng/modules/module1/text/page8a.htm.

${ }^{15}$ Bordowitz R, Morland K, Reich D. The use of an electronic medical record to improve documentation and treatment of obesity. Fam Med 2007; 39:274-279.

${ }^{16}$ Cull WL, O'Connor KG, Sharp S, Tang $\mathrm{SF}$. Response rates and response bias for 50 surveys of pediatricians. Health Serv Res 2005; 40:213-226.

${ }^{17}$ Sheehan K. E-mail survey response rates: A review. J Comput Media Commun 2001;6(2). Accessed at: http://jcmc. indiana.edu/vol6/issue2/sheehan.html.
${ }^{18}$ Thorpe C, Ryan B, McLean S, et al. How to obtain excellent response rates when surveying physicians. Fam Pract 2009; 26:65-68.

${ }^{19}$ Schaefer DR, Dillman DA. Development of a standard e-mail methodology: Results of an experiment. Public Opin Q 1998; 62:378-397.

${ }^{20}$ Schoenman JA, Berk ML, Feldman JJ, Singer A. Impact of differential response rates on the quality of data collected in the CTS physician survey. Eval Health Prof 2003; 26:23-42.

${ }^{21}$ Reifsnider E, Flores-Vela A, BeckmanMendez D, Nguyen H, Keller C, DowdallSmith S. Perceptions of children's body sizes among mothers living on the TexasMexico border (La Frontera). Public Health Nurs 2006; 23:488-495.

Keywords: body weight, body mass index, perception, physicians, child preschool 